\title{
Differential Perception of Problem Behaviors between Parents, Teachers and Therapists
}

\author{
S. Venkatesan ${ }^{1}$, L. Lokesh ${ }^{2}$
}

\section{ABSTRACT}

Background: Identification, listing, and prioritizing problem behaviors, and identification of rewards require unanimity among caregivers for effective management of children. Differential perception between the child handlers can endanger behavior correction program. Method: This cross sectional survey enlists the nature, frequency and intensity of problem behaviors, examines rank order preferences for target setting, and elicits reward preferences as reported separately by 94 father-mother-teacher-therapist caregivers for and on behalf of their 31 children with intellectual/developmental disabilities. Data was collected using standardized problem behavior tool and evocative procedures like open ended interviews and key informant reports. Results: There is greater propensity toward externalizing than internalizing forms of problem behaviors in the children. The point prevalence overall frequency count of problem behaviors per respondent is 20.15 and per child is 15.44 . Significant differences and inverse correlations are seen between informants on all aspects of reporting frequency, intensity and/or types of problem behavior, their prioritizing and listing of rewards. Mothers report highest number of problem behaviors in their children compared to teachers, fathers and therapists. The implications of this poor agreement are presented and discussed for optimizing problem behavior remediation programs.

Keywords: Behavior Modification, Caregivers, Challenging Behaviors, Differential Perception, Functional Analysis, Intellectual \& Developmental Disabilities

Problem behavior management programs typically follow a sequence of steps requiring their listing, prioritizing, selection of targets for intervention, identification of rewards, making baseline observations on antecedents and consequences, before undertaking a functionalutilitarian analysis and making a choice on appropriate techniques for their correction (Walls \&

\footnotetext{
${ }^{1}$ Professor \& Head, Department of Clinical Psychology in All India Institute of Speech and Hearing, under Ministry of Health \& Family Welfare, Government of India, located at Manasagangotri, Mysore, Karnataka, India.

${ }^{2}$ Clinical Psychologist-Grade II, Department of Clinical Psychology in All India Institute of Speech and Hearing, under Ministry of Health \& Family Welfare, Government of India, located at Manasagangotri, Mysore, Karnataka, India

*Responding Author

(C) 2016, S Venkatesan, L Lokesh; licensee IJIP. This is an Open Access Research distributed under the terms of the Creative Commons Attribution License (http://creativecommons.org/licenses/by/2.0), which permits unrestricted use, distribution, and reproduction in any Medium, provided the original work is properly cited.
} 


\section{Differential Perception of Problem Behaviors between Parents, Teachers and Therapists}

Rauner, 2015; Barkley, 2013; Marr, 2010; Herbert \& Wookey, 2004; Peshawaria \& Venkatesan, 1992). The skill transfer and use of behavior modification techniques on ground level is full of challenges (Martin \& Pear, 2015). There are individual differences in caregivers on matters concerning how to manage problem behaviors in their children. One parent may be quite serious about the whole issue, while another may not. There could be difference of opinion on whether a given behavior is to be deemed as problematic or not. Even if some behaviors are agreed as 'troublesome', there may be disparities between caregivers on their observed frequency, intensity or magnitude. There could be disagreements on which behavior is to prioritized, how to undertaking baseline, and/or on which rewards are to be used at what time for a given child or group of children. Such disparities among caregivers turn into an advantage for the child. It would be worthwhile to empirically examine the ground situation on what happens when children show problem behaviors. How do caregivers view or observe problem behaviors in their children? Are there any similarities or differences on the nature, intensity and extensity of problem behaviors reported for their children between parents, teachers and therapists? Do they all agree or disagree on which problem behavior need to be tackled first? Do they all use similar rewards at least nearly in the same manner?

It appears that there is no settled opinion on how parents, teachers, and other caregivers view the nature, types, intensity or extensity of problem behaviors in their own children. Unfortunately, a minimal requirement for success of behavior remediation program is that all the involved stakeholders agree about which problems to address. Wherein a treatment program between the child-parent-teacher-therapist quartets begins without consensus on a single problem, chances are high that such interventions will fail (Hawley \& Welsz, 2003). Going by the preceding research questions, this study is attempted with the general aim to explore the nature, frequency and intensity of problem behaviors, prioritizing as well as reward identification by key caregivers of Children with Intellectual Developmental Disabilities (CIDD). The specific objectives are:

1. To enlist the nature, frequency and intensity of problem behaviors separately as reported by fathers, mothers, teachers and therapists involved in management of their CIDD;

2. To examine the rank order preferences of prioritizing problem behaviors for remediation as reported separately by fathers, mothers, teachers and therapists involved in management of their CIDD; and,

3. To elicit the reward preferences as given separately by fathers, mothers, teachers and therapists involved in management of their CIDD.

\section{METHOD}

This study uses cross sectional randomized survey design combining behavior observation, use of standardized problem behavior assessment tools, and key informant interview techniques to elicit the different perceptions on or about identification, listing and prioritizing of problem behaviors as well as preferred rewards for CIDD by their caregivers including father, mother, 


\section{Differential Perception of Problem Behaviors between Parents, Teachers and Therapists}

teacher, as well as therapist respondents. The key variables targeted in this enquiry are: 'problem behavior' and 'rewards'.

\section{Operational Definitions}

Skill or adaptive behavior contrast maladaptive, dysfunctional, non-productive problem behaviors. Problem behaviors are considered as negative, undesirable, or challenging. By definition, such behaviors are deemed as not being age or situation appropriate, interfering in the learning of new behaviors, harmful to self or others, occurring in magnitude sufficient to cause stress on others (Venkatesan, 2004). A distinction is to be made between behavior problems of non-clinical nature from those which is part of full-fledged clinical diagnostic conditions like Opposition Defiant Disorder, Attention Deficit/Hyperactivity Disorder, or Conduct Disorder (APA, 2013; WHO, 2013). A developmental, socio-economic and cultural perspective is vital for identification or definition of behavioral abnormalities in children (Venkatesan, 2010). Bedwetting, avoidance of strangers or fear of darkness, for example, in a particular age is typical and beyond a developmental stage, they are viewed as problem behavior. More than being a passing age related phenomenon, persisting behavior problems are shown to have long term negative outcome for affected children, their family and society (Sroufe \& Rutter, 1984).

The term 'reward' as explained in this study refer to things, activities or events liked or preferred by an individual and thereby which would increase the probability of occurrence for that behavior for that person to behave in the same manner again and again. Rewards come in many forms and are classified in different ways. The classification of rewards used herein covers primary or edibles, activities, things or materials, social, tokens, sensory and privileges or positions respectively.

\section{Participants}

Based on convenience sampling, 94 respondents including fathers (N: 21), mothers (N: 24), teachers (N: 23) and therapists (N: 26) of 31 CIDD in age range between 4-12 years (Mean: 7.56; SD: 3.11) were recruited for this study. The teachers were handling such children either at their regular or special schools or during home tuitions. The therapists were post graduate level interns or higher with background from disciplines like speech language pathology or psychology designated to provide one-to-one therapy to the affected sample of children. The father-mother participants, although involved separately during data collection, included single and both parents for a given child.

\section{Tools}

Problem behavior assessment was undertaken by using eliciting and evocative procedure. Eliciting techniques involved use of formal checklist, such as, Problem Behavior Survey Schedule (PBSS; Venkatesan, 2015; 2013). Evocative techniques like open ended non-directive interviews and key-informant reports based on field observation was used. The PBSS is 100 item 
tool grouped under 11 domains. The scoring of each child on PBSS is carried out on two counts: 'Frequency Count Score' (FCS) based on presence or absence of given problem behaviors; and 'Intensity Count Score' (ICS). The former is marked as 'present' (Score: One) or 'absent' (Score: Zero). The latter is calculated on a 3-point rating scale: 'never' (Score: Zero), 'occasionally' (Score: One), and 'frequently' (Score: Two). The maximum possible FCS on PBSS is 100 and ICS is 200 for a given child. The inter-rater reliability coefficient for PBSS is reported as 0.91 (p: <0.001) and 3-week test-retest reliability is 0.89 (p: <0.001).

\section{Procedure}

The respondents were instructed to fill the PBSS for or on behalf of their child being handled in their respective school, home and/or therapy setting. Further, they were individually interviewed on a semi-structured response protocol to elicit details on what they deemed would be the things, events, or activities which may have reward value for their child. The collected data sets were in the form of frequency, intensity and total counts of problem behaviors identified, listed and prioritized by individual respondents. It also covered a list of rewards presumed by them as 'effective' while working with their children. The domain wise classification and categorization of problem behaviors as given in the tool used for the study was retained. Data collection was initiated after securing informed consent from the participants as mandated by the ethical guidelines in the institute (Venkatesan, 2009). The period of study extended between JanuaryDecember, 2015. All data entry, consolidation, mining and statistical analysis were carried out on IBM SPSS Statistics, 16.0 (Brace, Kemp \& Snelgar, 2012).

\section{RESULTS}

The results are arranged in sequential sub-headings: (a) Distribution of Problem Behaviors; (b) Correlation Analysis; (c) Ranking of Prioritized Problem Behaviors; and (d) Identification and Reporting of Rewards

\section{Distribution of Problem Behaviors:}

Even as different overall profiles of frequency, intensity and cumulative raw scores emerge without statistically significant differences ( $\mathrm{p}$ : $>0.05$ ), there appears to be greater propensity toward externalizing than internalizing forms of problem behaviors in the children (Table 1).

Insert Table 1 about Here

Scores on PBSS across respondents (Table 2) show that mothers (N: 24; Mean: 21.83; SD: 6.49) report highest frequency of externalizing problem behaviors against least number of internalizing problem behaviors by teachers (N: 23; Mean: 5.83; SD: 1.80). A high intensity of externalizing problem behaviors (N: 24; Mean: 29.66; SD: 9.16) and internalizing problem behaviors (N: 24; Mean: 14.29; SD: 4.58) is also reported by mothers. The least intensity of externalizing problem behaviors (N: 26; Mean: 8.96; SD: 3.07) is reported by therapists and lowest internalizing 


\section{Differential Perception of Problem Behaviors between Parents, Teachers and Therapists}

problem behaviors (N: 23; Mean: 7.43; SD: 2.38) is reported by teachers. As it appears, mothers are reporting twice the frequency for occurrence of externalized problem behaviors as fathers (N: 21; Mean: 10.14; SD: 3.93) and thrice as much as therapists (N: 26; Mean: 7.23; SD: 2.54). Likewise, their measured intensity of internalized problem behaviors (N: 24; Mean: 11.08; SD: 3.87) is also twice as much reported by teachers (N: 23; Mean: 5.83; SD: 1.80). These trends may be since mothers are frequently required to spend most of the time in a given day with the affected child as compared to evening or week-end visits by fathers, part-of-the-day-care rendered by teachers and only hourly consultations given by therapists. This is reiterated by the observation that the reported intensity of externalized problem behaviors are twice as much low with fathers (N: 21; Mean: 12.95; SD: 4.88) and thrice as much low as therapists (N: 26; Mean: 8.96; SD: 3.07). Even as mothers admit to greater difficulty with problem behaviors, there is poor agreement in the estimates of frequency, intensity and total scores on PBSS as given by the four caregivers (p: <0.001). Going by sub-types of problem behaviors, 'violent and destructive behaviors' are reported highest followed by 'misbehavior with others' and 'hyperactivity', while 'fears' and anti-social behaviors' is reported least across all respondents.

Insert Table 2 about Here

\section{Correlation Analysis}

Correlations were computed among four types of caregivers for frequency, intensity and overall scores on PBSS for 94 respondents on behalf of 31 children. The results suggest that moderate levels of correlations ( $\mathrm{r}:+.38$ to $.61, \mathrm{p}<.05$, two tailed) was statistically significant between teacher and therapists estimations of frequency and intensity of problem behaviors. Similarly, correlations were significant although ranging from inversely to positively for 6 out of 9 times (r: -.29 to +.49 ) between father and teacher. In general, the results suggest that correlations are by and large low and often inverse when it comes to frequency, intensity as well as total score counts on PBSS between all four varieties of respondents. This suggests that mothers see and report more problem behaviors as well as their greater intensities wherein the fathers of the same children do not do not mention as many. If at all, the teachers appear to go slightly along with the therapists of the same children with regard to their estimates on the frequency and intensity of problem behaviors on the same children.

Insert Table 3 about Here

\section{Rank Order of Prioritized Problem Behaviors:}

Respondents were independently asked to prioritize the identified and listed problem behaviors in their wards. The pooled rankings (Table 4) show poor agreement between all respondents. For example, while fathers prioritize 'misbehavior with others', 'anti-social behaviors', and 'odd behaviors' to be set as immediate targets for behavior correction in their children, mothers list 'rebellious behavior', 'violent and destructive behavior' and 'temper tantrums' as their 


\section{Differential Perception of Problem Behaviors between Parents, Teachers and Therapists}

immediate concerns. Although distinct from parent priorities, teacher and therapist informants appear to be more concerned about 'hyperactivity', 'misbehavior with others', 'repetitive behaviors' and/or 'odd behaviors'. All the respondents appear least concerned about 'fears' in the children. This implies that their concerns and priorities are different for identification and listing of problem behaviors to be targeted for correction in the children.

Insert Table 4 about Here

\section{Identification \& Reporting of Rewards:}

Rewards constitute the bedrock for the planning and implementation of any successful problem behavior correction program. The caregivers need to not only correctly identify, list and procure appropriate rewards for a given child or group of children, but also, dispense them properly by following the rules of consistency, constancy, clarity, immediacy, and variety. In the first place, it is seen that the number of items or events identified as rewards (N: 105) by informants (N: 94) is itself meager (Mean: 1.12). While this is so, it is also seen that caregivers seem to believe only in the potency of 'primary' rewards ( $\mathrm{N}$ : 55 out of 105; 52.38\%), followed by 'activity' rewards (N: 28 out of 105; 26.67\%) and 'material' rewards (N: 25 out of 105; 23.81\%)(Table 5).

Insert Table 5 about Here

\section{DISCUSSION}

The findings highlight the different frequency or intensity and total mean estimates of problem behaviors as reported by various caregivers, including fathers, mothers, teachers and therapists for the same target child or group of children. In an earlier study, 666 problem behaviors were reported by parents for and on behalf of a sample of 300 children targeted in that enquiry with a greater tendency for certain types of maladaptive behavior based on severity of intellectual disability, type of family, age and gender (Peshawaria, Venkatesan, \& Menon, 1990). There is a finding that typical children from dual parent family background, especially girls from rural areas, have significantly fewer behavior problems than their counterparts from single parent households (Ganesha \& Venkatesan, 2012). The typical theoretical profile emerging from another collateral study was one of a girl child raised in rural areas by a single younger aged father between 20-40 years as being the most vulnerable for problem behaviors characterized by anxious-depressed' type contrasting those brought up by single mothers who showed withdrawndepressed attention seeking somatic complaints (Ganesha \& Venkatesan, 2013). A majority of their sample was found to fall in the range of 'mild' and/or 'moderate' level with greater 'internalizing' than 'externalizing' problem behaviors in a survey of 1125 middle-high school urban children in a south Indian city (Vijayaprakash, Venkatesan \& Begum, 2013). That the concerns and priorities of different caregivers vary when it comes to identification and listing of problem behaviors to be targeted for correction in their children is shared by other studies. While it was shown that parents perceive 'disobedience' followed by 'physical harm toward others', 


\section{Differential Perception of Problem Behaviors between Parents, Teachers and Therapists}

'odd behaviors' and 'damages property' as most frequent problem behaviors in their children with intellectual disabilities, 'restless and physically overactive', 'inattentive', and 'misbehavior with others' were earmarked as topmost concerns for the same children by their teachers (Peshawaria, Venkatesan, Mohapatra \& Menon, 1990).

Such differences in interpersonal perception are stated on 'reported causes' and 'management strategies' used by parents of children with problem behaviors (Venkatesan \& Vepuri, 1993). For example, it was found that parents attribute 'cause' of problem behaviors as due to their 'child's primary condition' rather than due to anomalies in their own care giving, ineffective parenting, and/or environmental situations. Ritter (1989) noted how teacher tolerance influence their perception of problem behavior for adolescents identified as emotionally disturbed. Schaughency \& Lahey (1985) found mother ratings of their children's problem behaviors were significantly correlated with teacher ratings, but father ratings were not. This is contrary to the report by Webster-Stratton (1988) who found father perception of their child behaviors were significantly correlated with teacher ratings, but mother ratings were not.

Kolko \& Kazdin (1993) examined the correspondence among child, parent and teacher reports for their ratings on emotional and behavioral problems in 6-13 year old group to report moderate range, but not significantly different, correlations between parent and teacher informant ratings. In another study, modest and independent associations were found between teachers and parent reports on internalizing and externalizing child behavior problems than those between mother and father perspectives in the assessment of their children's behavior problems (Phares, Compas \& Howell, 1989).

That the value and power of other types of rewards, apart from expensive primary and material rewards, is not recognized or acknowledged by caregivers is supported by earlier studies (Venkatesan, Peshawaria \& Anuradha, 1996). Some studies show low agreement between multiple informants reporting only in some age groups or for certain types of children's behavior problems but not in others. For example, agreement between mother and father reports are reported high, whereas agreement between mother and teacher reports is lowest or disagreement between informants was highest for internalizing than externalizing problem behaviors (Grietens et al. 2004). Such informant discrepancies are attributed to the nature of relationships with their children (Treutler \& Epkins, 2003).

\section{CONCLUSION}

In sum, the results of this study highlight that the point prevalence overall frequency count of problem behaviors per respondent is 20.15 and per child is 15.44. Significant differences and inverse correlations are seen between informants on all aspects of reporting, prioritizing and listing of rewards. The number of other directed externalized problem behaviors reported per respondent (11.45) and per child (8.77) is higher than the inner directed internalized problem 


\section{Differential Perception of Problem Behaviors between Parents, Teachers and Therapists}

behaviors per respondent (8.70) and per child (6.66) in this sample of children. In relation to reported intensity of problem behaviors, there appears to be only a marginal difference between 1.30 and 1.33 out of a maximum of 3 between the internalized and externalized domains of problem behavior.

Analysis of overall frequency scores on PBSS across respondents show mothers report highest frequency of problem behaviors in their children compared to relatively less numbers by teachers, fathers and therapists. With regard to sub-types of problem behaviors, 'violent and destructive behaviors' are reported highest followed by 'misbehavior with others' and 'hyperactivity', while 'fears' and anti-social behaviors' get reported least across respondents.

Multiple correlation analysis show that mothers see and report more problem behaviors as well as estimate their greater intensities wherein fathers of the same children do not do not mention as many. If at all, the teachers appear to go in line with therapists with regard to their estimates on frequency and intensity of problem behaviors.

The concerns and priorities of caregivers are different when it comes to the first step of identification and rank order listing or prioritizing of problem behaviors to be targeted for correction in their children. The number of identified rewards by informants is minimal as also it is seen that caregivers seem to believe only in the potency of 'primary', 'activity' and 'material' rewards with little or no value and power being ascribed for other types of rewards.

The implications of this poor agreement across key caregivers on all aspects of identification, listing, estimating, or prioritizing problem behaviors in children has direct bearing upon the need to address this issue during all individualized and group based problem behavior remediation programs.

\section{Acknowledgments}

The author appreciates all those who participated in the study and helped to facilitate the research process.

\section{Conflict of Interests}

The author declared no conflict of interests.

\section{REFERENCES}

American Psychiatric Association. (2013). Diagnostic and Statistical Manual of Mental Disorders, $5^{\text {th }}$ ed. Washington, DC: Author.

Barkley, R.A. (2013). Defiant children: a clinician's manual for assessment and parent training. New York: The Guilford Press.

Brace, N., Kemp, R., \& Snelgar, R. (2012). SPSS for psychologists ( $^{\text {th }}$ ed.). New York: Palgrave Macmillan. 


\section{Differential Perception of Problem Behaviors between Parents, Teachers and Therapists}

Ganesha \& Venkatesan, S. (2012). Comparative profiles of problem behaviors in children from single versus dual parent families. Journal of Psychology, 3, 2, 89-98.

Ganesha \& Venkatesan, S. (2013). Domain and item wise principal component analysis of problem behaviors in children from single-dual parent families. International Journal of Psychology \& Psychiatry, 1, 2, 43-55.

Grietens, H., Ongheria, P., Prinzie, P., Gadeyne, E., Assche, V.V., Ghesquiere, P., \& Hellinickx, W. (2004). Comparison of mothers', fathers', and teachers' reports on problem behavior in 5- to 6-year-old children. Journal of Psychopathology and Behavioral Assessment, 26, 2, 137-146.

Hawley, K. M., \& Welsz, J.R. (2003). Child, parent and therapist (dis)agreement on target problems in outpatient therapy: The therapists dilemma and its implications. Journal of Consulting and Clinical Psychology, 71, 1, 62-70. DOI: http://dx.doi.irg/10.1037/0022006X.71.1.62

Herbert, M., \& Wookey, J. (2004). Managing children's disruptive behavior: a guide for practitioners working with parents and foster parents. West Sussex: John Wiley \& Sons.

Kolko, D. J., \& Kazdin, A. E. (1993), Emotional/behavioral problems in clinic and non-clinic children: correspondence among child, parent and teacher reports. Journal of Child Psychology and Psychiatry, 34, 991-1006. DOI: 10.1111/j.1469-7610.1993.tb01103.x

Marr, J.N. (2010). Manual of Behavior Modification: A Guide for Parents. New York: Xlibris Corporation

Martin, G., \& Pear, J. (2015). Behavior Modification: What it is and how to do it. Oxon: Routledge.

Peshawaria, R., \& Venkatesan, S. (1992). Behavioral approaches in teaching mentally handicapped children: A manual for teachers. Secunderabad: National Institute for the Mentally Handicapped.

Peshawaria, R., Venkatesan, S., \& Menon, D.K. (1990). Behavior problems in mentally handicapped persons: An analysis of parent needs. Indian Journal of Clinical Psychology, 17, 2, 63-70.

Peshawaria, R., Venkatesan, S., Mohapatra, B., \& Menon, D.K. (1990). Teachers' perception of problem behaviors among mentally handicapped persons in special school settings. Indian Journal of Disability \& Rehabilitation, 4, 1, 23-30.

Phares, V., Compas, B. E., \& Howell, D. C. (1989). Perspectives on child behavior problems: Comparisons of children's self-reports with parent and teacher reports. Psychological Assessment: A Journal of Consulting and Clinical Psychology, 1, 1, 68-71. DOI: http://dx.doi.org/10.1037/1040-3590.1.1.68.

Ritter, D.R. (1989). Teachers' perceptions of problem behavior in general and special education. Exceptional Children, 55, 6, 559-564. DOI: 10.1177/001440298905500610

Schaughency, E.A., \& Lahey, B.B. (1985). Mothers' and fathers’ perceptions of child deviance: roles of child behavior, parental depression, and mental satisfaction. Journal of Consulting and Clinical Psychology, 53, 5, 718-723. DOI: http://dx.doi.org/10.1037/0022-006X.53.5.718

Sroufe, L. A., \& Rutter, M. (1984). The domain of developmental psychopathology. Child Development, 55, 1, 17-29.

Treutler, C. M., \& Epkins, C. C. (2003). Are discrepancies among child, mother, and father reports on children's behavior related to parents' psychological symptoms 


\section{Differential Perception of Problem Behaviors between Parents, Teachers and Therapists}

and aspects of parent-child relationships? Journal of Abnormal Child Psychology, $31,1,13-27$.

Venkatesan, S. (2004). Children with developmental disabilities: A training guide for parents, teachers \& caregivers. New Delhi: Sage (India) Publications.

Venkatesan, S. (2009). Ethical Guidelines for Bio Behavioral Research. Mysore: All India Institute of Speech and Hearing.

Venkatesan, S. (2010). Cultural factors in clinical assessment: The Indian perspective. Indian Journal of Clinical Psychology, 37, 1, 75-85.

Venkatesan, S. (2013). Preliminary try out and validation of problem behavior survey schedule for children with developmental disabilities. Journal of Disability Management and Special Education. 3, 2, 9-22.

Venkatesan, S. (2015). Problem behavior survey schedule: Manual. Bangalore: Psychotronics.

Venkatesan, S., \& Vepuri, V.G.D. (1993). Parental perceptions of causes and management of problem behaviors in individuals with mental handicap. Disabilities \& Impairments. 7, 2, 29-37.

Venkatesan, S., Peshawaria, R., \& Anuradha, M.P. (1996). Reward preferences in parents/caregivers of children with mental handicaps. Indian Journal of Applied Psychology. 33, 1, 11-17.

Vijayaprakash, S.B., Venkatesan, S., \& Begum, K. (2013). Prevalence of behavior problems among school children and their demographic correlates. Guru Journal of Behavioral and Social Sciences, 1, 4, 203-212.

Walls, S., \& Rauner, D. (2015). Behavior management skills guide: practical activities and interventions for ages 3-18. Wisconsin: Premier Education Solutions.

Webster-Stratton, C. (1988). Mothers' and fathers' perception of child deviance: roles of parent and child behaviors and parent adjustment. Journal of Consulting and Clinical Psychology, 56, 6, 909-915. DOI: http://dx.doi.org/10.1037/0022-006X.56.6.909

WHO (2013). The ICD-10-CM codes and criteria. Retrieved from http://www.icd10data.com/ Search.aspx? search=autism \& codebook=AllCodes on 21-08-2013. 
Table 1, Domain Wise Distribution of PBSS Scores (N: 95 Respondents on behalf of 31 children)

\begin{tabular}{|l|c|c|c|c|}
\hline Domains of & \multirow{2}{*}{$\begin{array}{l}\text { Pumber } \\
\text { Problem }\end{array}$} & \multicolumn{3}{|c|}{ OVERALL } \\
\cline { 3 - 5 } & of Items & $\begin{array}{c}\text { Frequency } \\
\text { Score }\end{array}$ & $\begin{array}{c}\text { Intensity } \\
\text { Score }\end{array}$ & $\begin{array}{c}\text { Total } \\
\text { Score }\end{array}$ \\
\hline Violent \& Destructive Behavior & 16 & 437 & 566 & 1003 \\
\hline Temper Tantrums & 4 & 144 & 230 & 374 \\
\hline Misbehavior with Others & 14 & 286 & 353 & 639 \\
\hline Rebellious Behavior & 6 & 194 & 262 & 456 \\
\hline Antisocial Behaviors & 14 & 27 & 37 & 64 \\
\hline Externalizing* & $\mathbf{5 4}$ & $\mathbf{1 0 8 8}$ & $\mathbf{1 4 4 8}$ & $\mathbf{2 5 3 6}$ \\
\hline Self Injurious Behavior & 11 & 148 & 173 & 321 \\
\hline Repetitive Behaviors & 9 & 152 & 179 & 331 \\
\hline Odd Behaviors & 10 & 88 & 103 & 191 \\
\hline Hyperactivity & 3 & 226 & 350 & 576 \\
\hline Fears & 4 & 121 & 143 & 264 \\
\hline Others & 9 & 91 & 124 & 215 \\
\hline Internalizing** & $\mathbf{4 6}$ & $\mathbf{8 2 6}$ & $\mathbf{1 0 7 2}$ & $\mathbf{1 8 9 8}$ \\
\hline Overall Raw Scores & $\mathbf{1 0 0}$ & $\mathbf{1 9 1 4}$ & $\mathbf{2 5 2 0}$ & $\mathbf{4 4 3 4}$ \\
\hline
\end{tabular}

* For externalizing problem behaviors $\mathrm{X}^{2}: 4.0725$; $\mathrm{p}$ : 0.396; NS;

** For internalizing problem behaviors $\mathrm{X}^{2}$ : 7.0103; p: 0.135; NS;

Table 2, Distribution of Mean Scores on PBSS as reported by Different Respondents

\begin{tabular}{|c|c|c|c|c|c|c|c|c|c|c|c|c|c|}
\hline \multirow{2}{*}{ 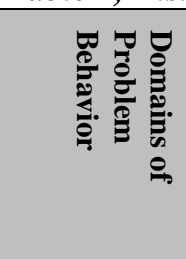 } & \multirow{2}{*}{ 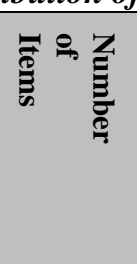 } & \multicolumn{4}{|c|}{$\begin{array}{c}\text { Frequency Score- } \\
\text { Respondent/s^s}\end{array}$} & \multicolumn{4}{|c|}{$\begin{array}{l}\text { Intensity Score- } \\
\text { Respondent } / \mathrm{s}^{\wedge} \wedge\end{array}$} & \multicolumn{4}{|c|}{ Total Score $\wedge \wedge \wedge$} \\
\hline & & 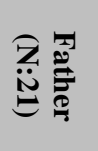 & 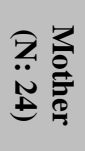 & 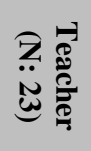 & 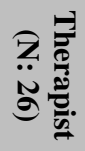 & 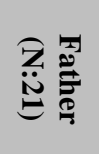 & 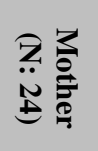 & 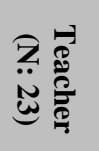 & 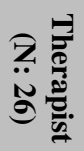 & 忌罚 & 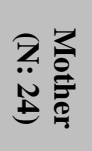 & 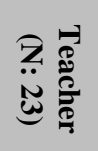 & 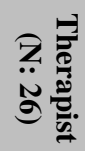 \\
\hline $\begin{array}{l}\text { Violent \& } \\
\text { Destructive } \\
\text { Behavior }\end{array}$ & 16 & 60 & 193 & 126 & 58 & 64 & 262 & 166 & 74 & 124 & 455 & 292 & 132 \\
\hline $\begin{array}{l}\text { Temper } \\
\text { Tantrums }\end{array}$ & 4 & 24 & 70 & 26 & 26 & 34 & 127 & 35 & 34 & 58 & 197 & 61 & 60 \\
\hline $\begin{array}{l}\text { Misbehavior } \\
\text { with Others }\end{array}$ & 14 & 51 & 100 & 82 & 53 & 72 & 111 & 106 & 64 & 123 & 211 & 188 & 117 \\
\hline $\begin{array}{l}\text { Rebellious } \\
\text { Behavior }\end{array}$ & 6 & 32 & 86 & 44 & 32 & 49 & 122 & 52 & 39 & 81 & 208 & 96 & 71 \\
\hline $\begin{array}{l}\text { Antisocial } \\
\text { Behaviors }\end{array}$ & 14 & 11 & 14 & 1 & 1 & 13 & 21 & 1 & 2 & 24 & 35 & 2 & 3 \\
\hline $\begin{array}{l}\text { Sub-Total } \\
\text { Externalizin } \\
\text { g Score } \uparrow\end{array}$ & 54 & 178 & 463 & 279 & 170 & 232 & 643 & 360 & 213 & 410 & 1106 & 639 & 383 \\
\hline Mean & & 10.14 & 21.83 & 13.70 & 7.23 & 12.95 & 29.66 & 17.39 & 8.96 & 22.62 & 51.92 & 31.04 & 16.27 \\
\hline SD & & 3.93 & 6.49 & 5.09 & 2.54 & 4.88 & 9.16 & 6.17 & 3.07 & 8.74 & 15.92 & 11.24 & 5.47 \\
\hline $\begin{array}{l}\text { Self Injurious } \\
\text { Behavior }\end{array}$ & 11 & 41 & 77 & 12 & 18 & 45 & 92 & 15 & 21 & 86 & 169 & 27 & 39 \\
\hline $\begin{array}{l}\text { Repetitive } \\
\text { Behaviors }\end{array}$ & 9 & 35 & 61 & 36 & 20 & 40 & 79 & 40 & 20 & 75 & 140 & 76 & 40 \\
\hline $\begin{array}{l}\text { Odd } \\
\text { Behaviors }\end{array}$ & 10 & 22 & 16 & 26 & 24 & 28 & 17 & 29 & 29 & 50 & 33 & 55 & 53 \\
\hline Hyperactivity & 3 & 44 & 65 & 47 & 70 & 60 & 105 & 74 & 111 & 104 & 170 & 121 & 181 \\
\hline Fears & 4 & 30 & 47 & 13 & 31 & 40 & 50 & 13 & 40 & 70 & 97 & 26 & 71 \\
\hline Others & 9 & 22 & 32 & 6 & 31 & 31 & 49 & 7 & 37 & 53 & 81 & 13 & 68 \\
\hline
\end{tabular}

(C) The International Journal of Indian Psychology, ISSN 2348-5396 (e)| ISSN: 2349-3429 (p) | 31 
Differential Perception of Problem Behaviors between Parents, Teachers and Therapists

\begin{tabular}{|c|c|c|c|c|c|c|c|c|c|c|c|c|c|}
\hline \multirow{2}{*}{ 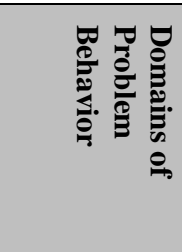 } & \multirow{2}{*}{ 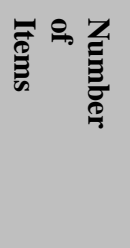 } & \multicolumn{4}{|c|}{$\begin{array}{l}\text { Frequency Score- } \\
\text { Respondent/s^} \wedge\end{array}$} & \multicolumn{4}{|c|}{ 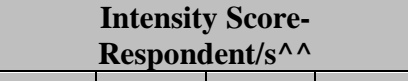 } & \multicolumn{4}{|c|}{ Total Score $\wedge \wedge \wedge$} \\
\hline & & 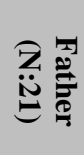 & 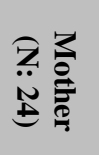 & 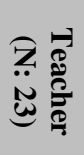 & 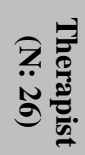 & 尽 & 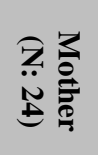 & 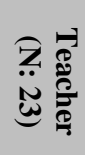 & 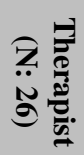 & 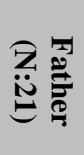 & 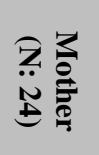 & 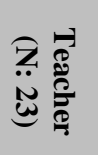 & 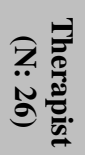 \\
\hline $\begin{array}{l}\text { Sub-Total } \\
\text { Internalizin } \\
\text { g Score } \uparrow\end{array}$ & 46 & 194 & 298 & 140 & 194 & 244 & 392 & 178 & 258 & 438 & 690 & 318 & 452 \\
\hline Mean & & 8.19 & 11.08 & 5.83 & 6.27 & 10.14 & 14.29 & 7.43 & 8.50 & 18.33 & 25.38 & 13.00 & 14.46 \\
\hline SD & & 3.28 & 3.87 & 1.80 & 2.11 & 5.01 & $\begin{array}{l}4.58 \\
\end{array}$ & 2.38 & 3.04 & 8.17 & 8.55 & 3.90 & 4.79 \\
\hline $\begin{array}{l}\text { Total Raw } \\
\text { Score }\end{array}$ & 100 & 372 & 761 & 419 & 364 & 476 & 1035 & 538 & 471 & 848 & 1796 & 957 & 835 \\
\hline
\end{tabular}

*For externalizing problem behaviors: $\wedge X^{2}$ : 36; df: 12; p: 0.001; $\wedge X^{2}: 76.22$;f: 12 ; p: 0.001; $\wedge \wedge X^{2}: 107.89$; df: 12; p: 0.001;

For internalizing problem behaviors: $\wedge X^{2}: 68.69$; df: 12; p: 0.001; $\wedge X^{2}: 146.27$;f: 12; p: 0.001; $\wedge \wedge X^{2}: 165.42$; df: 12; p:

0.001 ;

Table 3, Inter-Correlation Matrix on Distribution of Scores on PBSS as reported by Different Respondents

\begin{tabular}{|c|c|c|c|c|c|c|c|c|c|c|c|c|c|}
\hline \multicolumn{2}{|l|}{ Variable $\rightarrow$} & \multicolumn{4}{|c|}{ Frequency Score } & \multicolumn{4}{|c|}{ Intensity score } & \multicolumn{4}{|c|}{ Total Score } \\
\hline$\downarrow$ & 胥 & 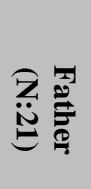 & 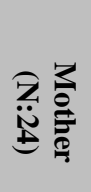 & 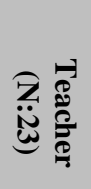 & 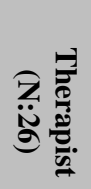 & 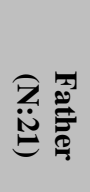 & 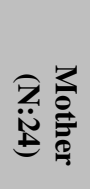 & 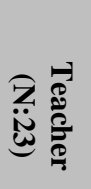 & 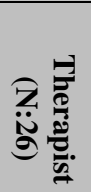 & 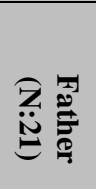 & 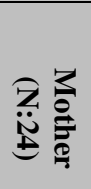 & 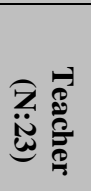 & 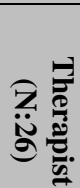 \\
\hline & Father & 1.00 & & & & 1.00 & & & & 1.00 & & & \\
\hline \multirow{3}{*}{$\begin{array}{l}\text { Frequency } \\
\text { Score }\end{array}$} & Mother & 0.11 & 1.00 & & & 0.16 & 1.00 & & & 0.15 & 1.00 & & \\
\hline & Teacher & -0.02 & -0.28 & 1.00 & & $\begin{array}{c}- \\
0.35 *\end{array}$ & -0.17 & 1.00 & & -0.29 & -0.22 & 1.00 & \\
\hline & Therapist & 0.39 & -0.07 & $0.61 *$ & 1.00 & 0.26 & 0.09 & $0.35 *$ & 1.00 & 0.28 & 0.02 & -0.22 & 1.00 \\
\hline \multirow{4}{*}{$\begin{array}{l}\text { Intensity } \\
\text { Score }\end{array}$} & Father & 1.00 & & & & 1.00 & & & & 1.00 & & & \\
\hline & Mother & -0.24 & 1.00 & & & -0.14 & 1.00 & & & -0.17 & 1.00 & & \\
\hline & Teacher & $\begin{array}{c}- \\
0.43 *\end{array}$ & 0.13 & 1.00 & & $\begin{array}{c}- \\
0.39 * \\
\end{array}$ & 0.32 & 1.00 & & $\begin{array}{c}- \\
0.43 * \\
\end{array}$ & 0.24 & 1.00 & \\
\hline & Therapist & 0.01 & 0.08 & $0.38 *$ & 1.00 & 0.09 & 0.30 & $0.43 *$ & 1.00 & 0.10 & 0.15 & $0.37 *$ & 1.00 \\
\hline \multirow{4}{*}{$\begin{array}{l}\text { Total } \\
\text { Score }\end{array}$} & Father & 1.00 & & & & 1.00 & & & & 1.00 & & & \\
\hline & Mother & $0.40 *$ & 1.00 & & & 0.32 & 1.00 & & & $0.39 *$ & 1.00 & & \\
\hline & Teacher & -0.15 & -0.29 & 1.00 & & $\begin{array}{c}- \\
0.49 *\end{array}$ & -0.19 & 1.00 & & $\begin{array}{c}- \\
0.48 *\end{array}$ & -0.26 & 1.00 & \\
\hline & Therapist & 0.24 & -0.09 & $0.49 *$ & 1.00 & 0.01 & -0.17 & 0.33 & 1.00 & 0.03 & -0.11 & $0.42 *$ & 1.00 \\
\hline $\begin{array}{l}\text { Total Raw } \\
\text { Score }\end{array}$ & & 372 & 761 & 419 & 364 & 476 & 1035 & 438 & 471 & 848 & 1796 & 957 & 835 \\
\hline Mean & & 17.7 & 31.8 & 18.3 & 13.9 & 22.57 & 43.13 & 23.39 & 18.12 & 40.00 & 74.8 & 41.3 & 31.8 \\
\hline SD & & 6.03 & 9.41 & 5.19 & 3.19 & 8.42 & 13.26 & 5.94 & 3.88 & 14.10 & 23.0 & 11.0 & 6.68 \\
\hline
\end{tabular}

(C) The International Journal of Indian Psychology, ISSN 2348-5396 (e)| ISSN: 2349-3429 (p) | 32 
Table 4, Mean Rank Order Distribution of Prioritized Problem Behavior for Intervention by Respondents

\begin{tabular}{|l|c|c|c|c|c|}
\hline \multirow{2}{*}{ Problem Behavior Domains } & \multirow{2}{*}{$\begin{array}{l}\text { Number } \\
\text { of }\end{array}$} & \multicolumn{4}{|c|}{ Respondent Rankings } \\
\cline { 3 - 6 } & Items & $\begin{array}{l}\text { Father } \\
\text { (N: 21) }\end{array}$ & $\begin{array}{c}\text { Mother } \\
\text { (N: 24) }\end{array}$ & $\begin{array}{c}\text { Teacher } \\
\text { (N: 23) }\end{array}$ & $\begin{array}{c}\text { Therapist } \\
\text { (N: 26) }\end{array}$ \\
\hline Violent \& Destructive Behavior & 16 & 4 & 2 & 5 & 4 \\
\hline Temper Tantrums & 4 & 6 & 3 & 7 & 5 \\
\hline Misbehavior with Others & 14 & 1 & 5 & 2 & 3 \\
\hline Rebellious Behavior & 6 & 8 & 1 & 7 & 6 \\
\hline Antisocial Behaviors & 14 & 2 & 10 & 4 & 8 \\
\hline Externalizing $\uparrow$ & $\mathbf{5 4}$ & & & & \\
\hline Self Injurious Behavior & 11 & 9 & 4 & 8 & 7 \\
\hline Repetitive Behaviors & 9 & 5 & 7 & 6 & 2 \\
\hline Odd Behaviors & 10 & 3 & 8 & 3 & 9 \\
\hline Hyperactivity & 3 & 7 & 6 & 1 & 1 \\
\hline Fears & 4 & 10 & 9 & 9 & 10 \\
\hline Others & 9 & 11 & 11 & 10 & 11 \\
\hline Internalizing $\uparrow$ & $\mathbf{4 6}$ & & & & \\
\hline Overall & $\mathbf{1 0 0}$ & & & & \\
\hline
\end{tabular}

Kruskal-Wallis Adjusted H: 0.041; df: 3; p: 0.998; NS;

Table 5, Distribution of Identified \& Reported Types of Rewards by Respondents for or on behalf of CWDD

\begin{tabular}{|c|c|c|c|c|c|c|}
\hline \multirow[t]{2}{*}{ Ranks } & \multirow{2}{*}{$\begin{array}{l}\text { Listed } \\
\text { Rewards }\end{array}$} & \multicolumn{4}{|c|}{ Respondents } & \multirow[b]{2}{*}{$\begin{array}{c}\text { Total } \\
\text { (N: 105) }\end{array}$} \\
\hline & & $\begin{array}{l}\text { Father } \\
\text { (N: 22) }\end{array}$ & $\begin{array}{l}\text { Mother } \\
\text { (N: } 33)\end{array}$ & $\begin{array}{l}\text { Teacher } \\
(\mathrm{N}: 24)\end{array}$ & $\begin{array}{c}\text { Therapist } \\
\text { (N: 26) }\end{array}$ & \\
\hline I & Primary & 11 & 24 & 13 & 7 & 55 \\
\hline II & Activity & 4 & 8 & 9 & 7 & 28 \\
\hline III & Material & 3 & 9 & 7 & 6 & 25 \\
\hline IV & Social & 2 & 4 & 7 & 6 & 19 \\
\hline $\mathrm{V}$ & Token & - & 3 & 7 & 6 & 16 \\
\hline VI & Sensory & - & 2 & 7 & 6 & 15 \\
\hline \multirow[t]{2}{*}{ VII } & Privileges & - & 2 & 4 & 3 & 9 \\
\hline & Total & 20 & 52 & 54 & 41 & 167 \\
\hline
\end{tabular}

How to cite this article: S Venkatesan, L Lokesh (2016), Differential Perception of Problem Behaviors between Parents, Teachers and Therapists, International Journal of Indian Psychology, Volume 3, Issue 4, No. 64, ISSN 2348-5396 (e), ISSN: 2349-3429 (p), DIP:18.01.118/20160304, ISBN: 978-1-365-32519-9 